\title{
PENGARUH HYPNOBREASTFEEDING PADA IBU HAMIL TRIMESTER III TERHADAP KECUKUPAN ASI PADA BAYI DI PUSKESMAS KAHURIPAN KECAMATAN TAWANG KOTA TASIKMALAYA TAHUN 2018
}

\author{
Igna Siti Napilah $^{1)}$, Hj. Yulia Herliani ${ }^{1}$, Endang Astiriyani ${ }^{1)}$ \\ ignnapillah@gmail.com \\ 1) Jurusan Kebidanan Poltekkes Kemenkes Tasikmalaya, Jawa Barat
}

\begin{abstract}
ABSTRAK
Menyusui adalah proses pemberian ASI kepada bayi sejak lahir oleh ibu setelah melahirkan. Beberapa faktor bisa menghambat ketersediaan ASI sehingga menyebabkan bayi tidak cukup ASI, salah satunya adalah faktor psikologis ibu. Hypnobreastfeeding dapat membantu ibu meningkatkan produksi ASI dan mengurangi stress laktasi dengan cara menanamkan afirmasi positif ke dalam pikiran. Penelitian ini bertujuan untuk mengetahui pengaruh Hypnobreastfeeding terhadap kecukupan ASI pada bayi.

Penelitian ini menggunakan desain penelitian quasi experiment design dengan rancangan penelitian postest only control group design. Populasi yaitu 50 orang ibu hamil multigravida di wilayah kerja Puskesmas Kahuripan. Teknik pengambilan sampling yaitu total sampling dengan kriteria inklusi dan eksklusi, terdiri dari 25 orang dengan perlakuan Hypnobreastfeeding, dan 25 orang sebagai kelompok kontrol. Analisis univariat dan bivariat dengan menggunakan uji Mann Withney U Test. Kecukupan ASI dengan kategori cukup diperoleh hasil sebesar 52\% pada kelompok intervensi dan sebesar 24\% pada kelompok kontrol. Hasil uji Mann Withney U Test diperoleh hasil dengan $\left(\rho_{\text {value }}\right)$ 0,020 kurang dari $\alpha(0,05)$ sehingga $\mathrm{H0}$ ditolak atau terdapat pengaruh hypnobreastfeeding terhadap kecukupan ASI pada bayi.

Terdapat pengaruh hypnobreastfeeding terhadap kecukupan ASI pada bayi. Diharapkan bidan terus memberikan pelayanan maksimal untuk keberhasilan ibu menyusui khususnya dengan melakukan Hypnobreastfeeding ini.
\end{abstract}

Kata Kunci : Ibu Hamil Trimester III, Kecukupan ASI, Hypnobreastfeeding

\begin{abstract}
Breastfeeding is the process of giving breast milk to the newborn baby by the mother after childbirth. Several factors can inhibit the availability of breast milk, causing the baby not enough milk, one of which is the psychological factors of the mother. Hypnobreastfeeding can help mothers increase milk production and reduce lactation stress by implanting positive affirmations into the mind. This study aims to determine the effect of Hypnobreastfeeding on breast milk sufficiency in infants.

This research uses quasi experiment design research design with posttest only control group design research. The population of 50 multigravida pregnant women in the working area of Puskesmas Kahuripan. Sampling technique that is total sampling with inclusion and exclusion criteria, consist of 25 people with Hypnobreastfeeding treatment, and 25 people as control group. Univariate and bivariate analysis using Mann Withney U Test.

Adequacy of breast milk with sufficient category resulted in $52 \%$ in the intervention group and by $24 \%$ in the control group. Mann Withney U Test test results obtained results with ( $\rho$ value) 0.020 less than a (0.05) so that $\mathrm{HO}$ rejected or there is influence hypnobreastfeeding on breast milk adequacy in infants.

There is a hypnobreastfeeding effect on the adequacy of breast milk in infants. It is expected midwives continue to provide maximum services for the success of breastfeeding mothers especially by doing this Hypnobreastfeeding.
\end{abstract}

Keywords : Pregnant Trimester III, Breast Milk Sufficiency, Hypnobreastfeeding 


\section{PENDAHULUAN}

Periode 1000 Hari Pertama Kehidupan sering disebut window of opportunities atau sering juga disebut periode emas (golden period) didasarkan pada kenyataan bahwa pada masa janin sampai anak usia dua tahun terjadi proses tumbuh kembang yang sangat cepat dan tidak terjadi pada kelompok usia lain (Kemenkes, 2012). Hal yang mendukung keberhasilan periode 1000 Hari Pertama Kehidupan adalah dengan melakukan Inisiasi Menyusui Dini dan ASI Eksklusif. ASI merupakan makanan yang bergizi sehingga tidak memerlukan tambahan komposisi. Disamping itu ASI mudah dicerna oleh bayi dan langsung terserap. Menyusui adalah proses paling penting dalam membentuk 1000 Hari Pertama Kehidupan anak.

Kelancaran produksi ASI dipengaruhi oleh banyak faktor seperti, frekuensi pemberian ASI, berat bayi saat lahir, usia kehamilan saat bayi lahir, usia ibu dan paritas, stress dan penyakit akut, IMD, perawatan payudara, penggunaan alat kontrasepsi, dan status gizi (Ferial, 2013). Sering ditemukan ibu yang mengalami kesulitan diawal menyusui seperti kelelahan, ASI sedikit, puting susu lecet, gangguan tidur malam hari, dan stress yang berhubungan dengan peran baru, hal itu dapat menjadi sumber stress ibu. Ibu yang cemas dan stress dapat mengganggu laktasi hingga mempengaruhi produksi ASI karena menghambat pengeluaran ASI (Ambarwati, 2009). Semuanya itu bisa membuat ibu tidak berhasil menyusui. Jika ibu mengalami gangguan emosi, maka kondisi itu bisa mengganggu proses let down reflek yang berakibat ASI tidak keluar, sehingga bayi tidak mendapat ASI dalam jumlah yang cukup, dan bayi pun akan terus menangis. Ketersediaan ASI yang lancar pada ibu menyusui akan membantu kesuksesan pemberian ASI Eksklusif selama 6 bulan, sehingga membantu bayi tumbuh dan berkembang dengan baik sesuai rekomendasi dari WHO (Ferial, 2013).

Menurut Pusdatin tahun 2016 presentase bayi yang mendapat ASI Eksklusif sampai 6 bulan di Jawa Barat adalah sebesar (39,6\%), sehingga Indonesia mendapat angka presentasi sebesar $(29,5 \%)$ dari 34 provinsi yang ada di Indonesia. Kota Tasikmalaya pada tahun 2016 menyumbangkan angka bayi yang mendapat ASI Eksklusif sebanyak 9.431 bayi atau sebesar $(80,3 \%)$. Capaian terendah persentase bayi yang diberi ASI Eksklusif per puskesmas di Kota Tasikmalaya menurut data KIA Dinas Kesehatan Kota Tasikmalaya adalah Puskesmas Bungursari sebesar (75,6\%), Puskesmas Karang Anyar dan Puskesmas Sangkali sebesar (76,6\%), dan Puskesmas Kahuripan sebesar $(76,9 \%)$.

Selain menyebabkan gagal tumbuh pada periode 1000 hari pertama kehidupan, bayi yang tidak cukup ASI bisa mengalami diare dan pneumonia. Angka kejadian diare di Jawa Barat pada tahun 2016 adalah $(73,8 \%)$ kasus ditangani dan untuk angka kejadian pneumonia di Jawa Barat pada tahun 2016 adalah 169.791 jiwa dan sebanyak 60.941 
jiwa terjadi pada balita $<1$ tahun. Jumlah kasus diare pada tahun 2016 di Kota Tasikmalaya terjadi sebanyak 16.808 kasus. Jika dibandingkan dengan tahun 2015 telah terjadi peningkatan dengan kejadian semula sebanyak 16.439 kasus. Jumlah balita penderita pneumonia yang ditemukan dan ditangani tahun 2016 di Kota Tasikmalaya sebanyak 2.612 kasus. Jumlah tersebut mengalami kenaikan yang cukup signifikan bila dibandingkan dengan tahun sebelumnya.

Beberapa upaya yang dapat dilakukan ibu sendiri untuk mengurangi stress laktasi adalah dengan melakukan olahraga teratur seperti yoga dan senam, memperbaiki pola tidur ibu dan memenuhi asupan makanan yang baik bagi ibu menyusui. Salah satu cara yang dapat membantu ibu meningkatkan produksi ASI dan mengurangi stress laktasi ibu adalah dengan melakukan Hypnobreastfeeding.

Hypnobreastfeeding adalah upaya alami menanamkan niat ke pikiran bawah sadar kita, untuk menghasilkan ASI yang cukup untuk kepentingan bayi. Relaksasi hypnobreastfeeding mampu menghadirkan rasa santai, nyaman dan tenang selama menyusui dengan demikian maka seluruh sistem di dalam tubuh akan berjalan jauh lebih sempurna sehingga proses menyusui pun menjadi proses yang penuh arti dan menyenangkan baik bagi ibu maupun bagi bayi (Aprillia, 2014). Cara ini bisa digunakan bagi ibu yang mengalami kesulitan dan stress laktasi. Hanya dengan menggunakan afirmasi positif ke dalam pikiran bisa membantu ibu sukses menyusui dan bisa memenuhi kecukupan ASI pada bayi. Terlebih lagi Hypnobreastfeeding ini bisa dilakukan sendiri di rumah. Menurut penelitian yang dilakukan oleh Armini di Denpasar tahun 2016, Hypnobreastfeeding dapat memenuhi kebutuhan ASI bayi sehingga ibu berhasil pada masa menyusui.

Berdasarkan latar belakang tersebut diatas, peneliti ingin mengetahui pengaruh Hypnobreastfeeding terhadap kecukupan ASI pada bayi terlebih lagi metode ini belum pernah dilakukan oleh ibu hamil ataupun ibu menyusui di Puskesmas Kahuripan Kecamatan Tawang, Kota Tasikmalaya.

\section{METODE PENELITIAN}

Penelitian ini merupakan penelitian quasi experiment design. Pendekatan desain penelitian dengan Postest Only Control Group Design. Rancangan ini memungkinkan peneliti mengukur pengaruh perlakuan pada kelompok eksperimen dengan cara membandingkan kelompok tersebut dengan kelompok kontrol (Nursalam, 2003). Pada penelitian ini, kelompok perlakukan diberikan intervensi berupa penerapan metode hypnobreastfeeding kepada ibu hamil trimester III dan kelompok kontrol diberi pendidikan kesehatan mengenai teknik menyusui yang benar. Populasi penelitian ini adalah seluruh ibu hamil multigravida sebanyak 50 orang. teknik sampel yang digunakan adalah dengan menggunakan teknik Total Sampling dengan kriteria inklusi dan eksklusi. 


\section{HASIL DAN PEMBAHASAN}

1. Analisis Univariat

Tabel. 1. Distribusi Frekuensi Kecukupan ASI pada Bayi di Puskesmas Kahuripan Kecamatan Tawang Kota Tasikmalaya Tahun 2018

\begin{tabular}{llccccc}
\hline \multirow{2}{*}{ No } & \multirow{2}{*}{ Kecukupan ASI } & \multicolumn{2}{c}{$\begin{array}{c}\text { Kelompok } \\
\text { Eksperimen }\end{array}$} & \multicolumn{2}{c}{ Kelompok Kontrol } \\
\cline { 3 - 6 } & & F & \% & f & \% \\
\hline 1 & Cukup & 13 & 52,0 & 5 & 20,0 \\
2 & Kurang & 12 & 48,0 & 20 & 80,0 \\
\hline \multicolumn{2}{r}{ Jumlah } & $\mathbf{2 5}$ & $\mathbf{1 0 0}$ & $\mathbf{2 5}$ & $\mathbf{1 0 0}$ \\
\hline
\end{tabular}

Berdasarkan Tabel. 1 di atas, diketahui bahwa kecukupan ASI pada bayi di Puskesmas Kahuripan Kecamatan Tawang Kota Tasikmalaya, pada kelompok eksperimen sebanyak 13 orang memiliki tingkat kecukupan ASI dengan kategori cukup (52\%), sedangkan pada kelompok kontrol yang memiliki kecukupan ASI dengan kategori cukup sebanyak 5 orang $(20 \%)$.

2. Analisis Bivariat

Tabel. 2. Pengaruh hypnobreastfeeding Pada Ibu Hamil Trimester III terhadap Kecukupan Asi pada Bayi di Puskesmas Kahuripan Kecamatan Tawang Kota Tasikmalaya Tahun 2018

\begin{tabular}{lc}
\hline \multicolumn{1}{c}{ Statistik } & Kecukupan ASI \\
\hline Mean Rank Kelompok Eksperimen & 29,50 \\
\hline Mean Rank Kelompok Kontrol & 21,50 \\
\hline Mann-Whitney U & 212,500 \\
\hline $\mathrm{Z}$ & $-2,333$ \\
\hline $\mathrm{p}_{\text {value }}$ & 0,020 \\
\hline
\end{tabular}

Berdasarkan Tabel. 2 diatas, diketahui bahwa pada kelompok eksperimen memiliki rata-rata sebesar 29,50 lebih tinggi dari pada kelompok kontrol yang memiliki rata-rata sebesar 21,50. Hal ini terlihat terdapat perbedaan antara kelompok eksperimen dan kelompok kontrol. Dilihat dari hasil uji menunjukkan nilai U sebesar 212,500. Setelah dikonversikan ke nilai $\mathrm{Z}$ maka besarnya adalah -2,333 dengan tingkat signifikansi ( $\left.\rho_{\text {value }}\right)$ 0,020 kurang dari $\alpha$ $(0,05)$, yang berarti bahwa terdapat pengaruh hypnobreastfeeding terhadap kecukupan ASI. 


\section{PEMBAHASAN}

1. Kecukupan ASI pada Bayi

Berdasarkan hasil penelitian kecukupan ASI pada bayi baik pada kelompok eksperimen maupun kelompok kontrol memiliki kecukupan ASI dengan kategori cukup, namun pada kelompok kontrol terdapat responden yang memiliki kecukupan ASI dengan kategori kurang yang cukup banyak. Diperoleh hasil sebesar (52\%) responden yang memiliki kecukupan ASI dengan kategori cukup pada kelompok intervensi, dan diperoleh hasil sebesar (24\%) responden yang memiliki kecukupan ASI dengan kategori cukup pada kelompok kontrol. Salah satu tanda kecukupan ASI adalah kenaikan berat badan bayi, setelah dilahirkan bayi akan mengalami penurunan berat badan, tetapi dalam 1-2 minggu kemudian bayi akan kembali ke berat badan lahirnya. Berat badan bayi bisa mencapai 2 kali lipat berat lahirnya pada usia 3-4 bulan, dan mencapai $3 x$ lipat berat lahirnya pada usia 1 tahun. Pastikan bayi mengalami kenaikan berat badan sesuai Kartu Menuju Sehat (KMS) setiap kali melakukan kunjungan berkala di posyandu atau fasilitas kesehatan lainnya (Annisa, 2015).

Hasil penelitian ini sejalan dengan Anita dan Prayogi (2017) mengatakan bahwa rata-rata produksi ASI perah pada 25 ibu dalam sehari sebelum hypnobreastfeeding menunjukkan jumlah yang berubah-ubah dengan peningkatan dan penurunan yang tidak menentu. Jumlah ASI yang dikeluarkan oleh payudara menunjukkan kelancaran ASI yang meliputi produksi dan pengeluaran ASI, dimana produksi ASI dikendalikan oleh prolaktin dan pengeluaran ASI oleh oksitosin.

Menurut Kuswandi (2009) hypnobreastfeeding adalah upaya alami menggunakan energi bawah sadar agar proses menyusui berjalan dengan aman dan lancar, serta Ibu dapat menghasilkan ASI yang mencukupi untuk kebutuhan tumbuh kembang bayi. Terdapat beberapa hal yang perlu dilakukan dalam melakukan Hypnobreastfeeding adalah mempersiapkan secara menyeluruh tubuh, pikiran dan jiwa agar proses pemberian ASI sukses. Meniatkan yang tulus dari batin untuk memberi ASI eksklusif pada bayi yang kita sayangi dan yakin bahwa semua ibu, bekerja atau di rumah, memiliki kemampuan untuk menyusui/memberi ASI pada bayinya (Armini, 2016). Kenyataannya, tidak semua ibu memiliki keyakinan yang sama sehingga menyebabkan bayi yang disusui memiliki perbedaan dalam hal kecukupan ASI. Keyakinan dan pikiran bawah sadar (subconscious mind) berperan $82 \%$ terhadap fungsi diri. Contoh ibu yang khawatir, cemas, kurang percaya diri akan menghambat produksi ASI. Pikiran bawah sadar ini merupakan tempat menyimpan informasi, sangat cerdas, serta pusat intuisi dan kreativitas (Aprilia, 2014). 
Dasar hypnobreastfeeding adalah relaksasi yang dicapai bila jiwa raga berada dalam kondisi tenang. Adapun timbulnya suasana relaksasi dapat didukung oleh ruangan/suasana tenang, menggunakan musik untuk relaksasi, ditambah aromatherapy, panduan relaksasi otot, napas dan pikiran (Armini, 2016). Untuk melakukan latihan hypnobreastfeeding, ibu dapat mempersiapkan beberapa hal. Faktor terpenting yang harus selalu diperhatikan dalam melakukan latihan relaksasi ini adalah faktor kenyamanan. Ibu harus merasa nyaman terhadap tubuhnya, pikirannya, pernapasannya suasananya, dan tanpa paksaan. Jika latihan hypnobreastfeeding dilakukan dengan terpaksa, maka akan tidak ada gunanya karena latihan ini membutuhkan rasa ikhlas dan cinta kasih (Nurbaety, 2014).

Selain kenyamanan dari dalam diri, ada faktor pendukung dari luar yang dapat digunakan untuk membuat ibu merasa lebih nyaman. Beberapa faktor tersebut diantaranya adalah alunan musik yang mendukung relaksasi, aromaterapi yang cocok dan aman digunakan untuk ibu hamil, suasana ruangan yang tenang, nyaman, dan tidak akan membuyarkan konsentrasi saat relaksasi sedang berlangsung, pilih posisi relaksasi yang paling nyaman, dapat dengan berbaring miring, berbaring terlentang atau bahkan duduk, kalau bisa gunakan ruangan yang ber-AC dan redup (Nurbaety, 2014).
Teknik hypnobreastfeeding sangat menguntungkan bagi ibu karena tanpa penggunaan obat-obatan, metode yang digunakan relatif sederhana, sehingga bisa dilakukan sendiri oleh ibu dirumah atau disebut sebagai teknik self hypnosis. SelfHypnosis secara sederhana berarti menghipnosis diri sendiri. Self hypnosis adalah suatu metode untuk "memasuki" pikiran bawah sadar, sehingga dapat melakukan "pemrograman ulang" terhadap pikiran bawah sadar, dan juga "pembersihan data", sehingga yang tersisa hanyalah hal-hal yang benar-benar "memberdayakan" diri. Prinsip dalam self hypnosis pada dasarnya adalah mengistirahatkan pikiran sadar kemudian memberikan sugesti berupa gambar dan afirmasi ke dalam pikiran bawah sadar. Kebanyakan orang gagal melakukan self hypnosis, karena tidak memiliki kesiapan program apa yang akan diinstal dalam pikirannya (Aprilia, 2010). Dalam hypnobreastfeeding, perubahan yang diinginkan adalah segala hal yang mempermudah dan memperlancar proses menyusui. Contoh kalimat sugesti atau afirmasinya: "ASI saya cukup untuk bayi saya sesuai dengan kebutuhannya", "Saya selalu merasa tenang dan rileks disaat mulai memerah".

Bahkan hypnobreastfeeding mampu membantu ibu yang mengalami kesulitan saat menyusui juga dapat membuat ibu mampu untuk relaktasi (Aprilia, 2014). 
Beberapa hal yang mendukung proses relaksasi hypnobreastfeeding menurut Nurbaeti (2014) keadaan tubuh yang relaks, dibantu dengan penggunaan musik dan suasana yang nyaman. Lalu yang kedua adalah faktor kenyamanan, ibu harus nyaman terhadap tubuhnya, pikirannya, pernapasannya, suasananya dan melakukan hypnobreastfeeding tanpa paksaan. Berdasarkan hal tersebut kecukupan ASI pada tiap-tiap responden kelompok intervensi memiliki perbedaan.

2. Pengaruh Hypnobreastfeeding Terhadap Kecukupan ASI Pada Bayi

Berdasarkan hasil penelitian diperoleh nilai $\mathrm{Z}$ sebesar -2,333 dengan tingkat signifikansi ( $\left.\rho_{\text {value }}\right)$ 0,020 kurang dari $\alpha(0,05)$, yang berarti bahwa terdapat pengaruh hypnobreastfeeding terhadap kecukupan ASI.

\section{Hypnobreastfeeding merupakan} upaya alami menggunakan energi bawah sadar agar proses menyusui berjalan dengan lancar, serta ibu dapat menghasilkan ASI yang mencukupi untuk kebutuhan tumbuh kembang bayi. Ibu dapat memberdayakan dirinya dengan melakukan relaksasi otot, nafas dan pikiran serta melalui sugesti positif guna mendapatkan keamanan, ketenangan dan kenyamanan selama proses menyusui. Melalui relaksasi hypnobreastfeeding ibu dapat lebih rileks dan percaya diri serta dapat menjalin hubungan batin yang erat dengan bayinya. Untuk itu hypnobreastfeeding dapat digunakan sebagai asuhan pelengkap, alternatif dan salah satu metode non farmakologi yang bermanfaat dalam mendukung keberhasilan menyusui (Latifah, 2015).

Hasil penelitian ini sejalan dengan Nuratri dkk (2015), dkk dengan judul : "Hypnobreastfeeding untuk Keberhasilan Pemberian ASI Eksklusif di RS. Panti Rapih Yogyakarta” dengan hasil penelitian responden yang mendapat Hypnobreastfeeding berhasil memberikan ASI Eksklusif sebesar (70,4\%) dibandingkan dengan yang tidak mendapat perlakukan Hypnobreastfeeding hanya $(43,3 \%)$ yang memberikan ASI Eksklusif.

Hypnobreastfeeding adalah upaya alami menanamkan niat ke pikiran bawah sadar kita, untuk menghasilkan ASI yang cukup untuk kepentingan bayi. Relaksasi hypnobreastfeeding mampu menghadirkan rasa santai, nyaman dan tenang selama menyusui dengan demikian maka seluruh sistem di dalam tubuh akan berjalan jauh lebih sempurna sehingga proses menyusui pun menjadi proses yang penuh arti dan menyenangkan baik bagi ibu maupun bagi bayi (Aprillia, 2014).

Keuntungan dan manfaat yang dapat diperoleh dari penggunaan hipnosis dalam hypnobreastfeeding adalah sebagai sarana relaksasi yang digunakan relatif sederhana sehingga mudah dipahami dan dipraktekkan oleh orang banyak, termasuk subjek, dapat dilakukan sendiri oleh subjek (ibu menyusui) dan cukup dibantu 
oleh satu terapis (bidan), dapat menyehatkan unsur tindakan, perilaku, hasrat, semangat, motivasi, inisiatif, kebiasaan buruk dan lain-lain, serta mempersiapkan ibu agar berhasil pada masa menyusui dan mempersiapkan bayi menjadi generasi yang sehat, cerdas dan kreatif (Armini, 2016).

\section{KESIMPULAN}

1. Kecukupan ASI pada bayi pada kelompok eksperimen diperoleh (52\%) yang memiliki kategori cukup dan pada kelompok kontrol sebesar (20\%) yang memiliki kategori cukup dalam kecukupan ASI pada bayi.

2. Terdapat pengaruh hypnobreastfeeding terhadap kecukupan ASI pada bayi di Puskesmas Kahuripan Kecamatan Tawang Kota Tasikmalaya, terbukti dengan tingkat signifikansi ( $\left.\rho_{\text {value }}\right) \quad 0,020$ kurang dari $\alpha(0,05)$.

\section{SARAN}

1. Melalui penelitian ini tenaga kesehatan khususnya bidan seharusnya terus memberikan pelayanan maksimal kepada ibu hamil khususnya sampai ibu berhasil melakukan ASI Eksklusif.

2. Dari hasil penelitian mahasiswa seharusnya lebih memperhatikan faktor pendukung keberhasilan Hypnobreastfeeding dan menambah ilmu yang dapat mendukung penerapan Hypnobreastfeeding.

\section{DAFTAR PUSTAKA}

Ambarwati, (2009), Asuhan Kebidanan Nifas, Jakarta :Mitra Cendekia

Annisa, (2015), Tanda Kecukupan ASI dan Keberhasilan Menyusui, tersedia dalam http://www.m.sehatmagz.com/pregnancy/t anda-kecukupan-asi-keberhasilanmenyusui/. Diakses pada tanggal $12 \mathrm{Mei}$ $\underline{2018}$

Aprilia, Yesie, (2010), Hipnostetri Rileks, Nyaman, dan Aman, Saat Hamil dan Melahirkan, GagasMedia, Jakarta

Aprillia, Yesie, (2014) tersedia dalam http://www.bidankita.com/hypnobreastfee ding-solusi-cerdas-meningkatkanproduksi-asi/. Diakses pada tanggal 10 November 2017

Armini, Ni Wayan, (2016), Hypnobreastfeeding awali suksesnya ASI Eksklusif, Jurnal Skala Husada Volume 13 Nomor 1, Denpasar

Budiarto, Eko, (2002), Biostatistik untuk Kedokteran dan Kesehatan Masyarakat. Dalam: Arlinda Sari Wahyuni. 2007. Statistika Kedokteran

Data dan Informasi Kesehatan, (2016), Profil Kesehatan Indonesia Tahun 2016

Depkes, (2007), Pelatihan Konseling Menyusui, Direktorat Jenderal Bina Kesehatan Masyarakat \& Direktorat Bina Gizi Masyarakat, Jakarta

Dinas Kesehatan Kota Tasikmalaya, (2016), Profil Kesehatan Kota Tasikmalaya Tahun 2016

Ferial, (2013), Biologi Reproduksi, Jakarta: Erlangga

Hidayat, Aziz Alimul, (2010), Metode Penelitian Kesehatan Paradigma Kuantitatif, Health Books Publishing, Surabaya

Kemenkes RI, (2012) tersedia dalam http://www.depkes.go.id/article/print/201 4/penuhi-kebutuhan-gizi-pada-1000-haripertama-kehidupan.html . Diakses pada tanggal 9 November 2017 
Kresnawan, dkk, (2007), Buku Pegangan Pelatih 'Pelatihan Asuhan Persalinan Normal Bahan Tambahan Inisiasi Menyusu Dini'. Depkes RI.

Kusmiati, Yuni, dkk, (2008), Perawatan Ibu Hamil, Penerbit Fitramaya, Yogyakarta

Kuswandi, Lani, (2009), Basic Hypnosis dan Hypnobirthing, Pro V Clinic, Bali

Latifah, Nurul, (2015), Pengaruh Hypnobreastfeeding Terhadap Keberhasilan Menyusui, tersedia dalam http://kebidananyes.blogspot.co.id/2015/1 2/pengaruh-hypnobreastfeedingterhadap.html. Diakses pada tanggal 15 Maret 2018

Manuaba, IAC., I Bagus, dan IB Gede, (2010), Ilmu Kebidanan, Penyakit Kandungan dan KB untuk Pendidikan Bidan. Edisi kedua. Jakarta: EGC

Monawdya, Wanda, (2013), Kebutuhan Ibu Hamil Sesuai dengan Tahap Perkembangannya, tersedia dalam http://majalahkebidanan.blogspot.co.id/. Diakses pada tanggal 23 November 2017

Notoatmodjo, Soekidjo, (2005), Metodologi Penelitian Kesehatan, Jakarta: PT. Rineka Cipta

Notoatmodjo, Soekidjo, (2010), Metodologi Penelitian Kesehatan, Jakarta: PT. Rineka Cipta

Nuratri, Astri Endah, dkk, (2013), Hypnobreastfeeding untuk Keberhasilan Pemberian ASI Eksklusif di RS Panti Rapih Yogyakarta, Jurnal STIKES Santo Borromeus, Bandung Barat

Nurbaety, Etty, (2014), Hypnobirthing Therapy, tersedia dalam https://kicaukisah.wordpress.com/tag/hyp nobirthing/. Diakses pada tanggal 16 Mei $\underline{2018}$

Nursalam, (2003), Konsep \& Penerapan Metodologi Penelitian Ilmu Keperawatan: Pedoman Skripsi, Tesis, dan Instrumen Penelitian Keperawatan. Jakarta. Salemba Medika

Prasetyo, Dwi Sunar, (2012), Buku Pintar Asi Eksklusif, Diva Press, Yogyakarta
Prawirohardjo, Sarwono, (2002), Ilmu Kebidanan, Jakarta: YBP-SP

Rahmawati, Anita, dan Prayogi, Bisepta, (2017), Hypnobreastfeeding Untuk Meningkatkan Produksi ASI Pada Ibu Menyusui yang Bekerja Tahun 2017, Seminar Nasional dan Gelar Produk Stikes Patria Husada Blitar, Blitar

Roesli, U, (2008), Inisiasi Menyusu Dini plus ASI Ekslusif. Jakarta : Pustaka Bunda

Roesli, Utami, dan Yohmi, Elizabeth, (2013), Manajemen Laktasi, tersedia dalam http://www.idai.or.id/artikel/klinik/asi/ma najemen-laktasi. Diakses pada tanggal 10 November 2017

Ronald, H. S, (2011), Pedoman dan Perawatan Balita agar Tumbuh Sehat dan Cerdas, Bandung : CV Nuansa Aulia

Saifuddin, Abdul Bahri (2008), Pelayanan Kesehatan Maternal Dan Neonatal, Jakarta : Bina Pustaka.

Saleha, Siti, (2009), Asuhan Kebidanan pada Masa Nifas, Jakarta: Salemba Medika

Stoppard, Miriam, (2002), Kehamilan dan Kelahiran. Jakarta :Mitra Media Publisher

Sulistyawati, Ari, (2009), Asuhan Kebidanan pada Masa Kehamilan. Jakarta: Salemba Medika

Susilowati H, Endang, (2006), Lebih jauh tentang kehamilan. Jakarta : Edsa Mahkota

Varney, Helen, dkk, (2007), Buku Ajar Asuhan Kebidanan Edisi 4, Penerbit Buku Kedokteran EGC, Jakarta

Widuri, Hesti, (2013), Cara Mengelola ASI Eksklusif, Edisi 1, Gosyen Publishin, Yogyakarta

Widyastuti, S, Adaptasi Psikososial Pada Masa Kehamilan. Tersedia dalam scribd.com/doc/37479306/AdaptasiPsikososial-Pada-Masa-Kehamilan. Diakses pada tanggal 11 November 2017

Yanti Damai, Sundawati, (2011), Asuhan Kebidanan Masa Nifas: Belajar Menjadi Bidan Profesional, PT. Refika Aditama, Bandung 